\title{
Air pollution, lagged effects of temperature, and mortality: The Netherlands 1979-87
}

\author{
J P Mackenbach, C W N Looman, A E Kunst
}

\begin{abstract}
Objective-To explore whether the apparent low threshold for the mortality effects of air pollution could be the result of confounding. Design-The associations between mortality and sulphur dioxide $\left(\mathrm{SO}_{2}\right)$ were analysed taking into account potential confounding factors.
\end{abstract}

Setting-The Netherlands, 1979-87.

Measurements and main results-The number of deaths listed by the day on which the death occurred and by the cause of death were obtained from the Netherlands Central Bureau of Statistics. Mortality from all causes and mortality from four large groups of causes (neoplasms, cardiovascular diseases, respiratory diseases, and external causes) were related to the daily levels of $\mathrm{SO}_{2}$ air pollution and potential confounders (available from various sources) using loglinear regression analysis. Variables considered as potential confounders were: average temperature; difference between maximum and minimum temperatures; amount of precipitation; air humidity; wind speed; influenza incidence; and calendar year, month, and weekday. Both lagged and unlagged effects of the meteorological and influenza variables were considered. Average temperature was represented by two variables-'cold', temperatures below $16 \cdot 5^{\circ} \mathrm{C}$, and 'warm', those above $16.5^{\circ} \mathrm{C}$ - to allow for the $V$ shaped relation between temperature and mortality. The positive regression coefficient for the univariate effect of $\mathrm{SO}_{2}$ density on mortality from all causes dwindles to close to zero when all potential confounding variables are taken into account. The most important of these represents the lagged (one to five days) effect of low temperatures. Low temperatures have strong lagged effects on mortality, and often precede relatively high $\mathrm{SO}_{2}$ densities in the Netherlands. Results were similar for separate causes of death. While univariate associations suggest an effect of air pollution on mortality in all four cause of death groups, multivariate analyses show these effects, including that on mortality from respiratory diseases, are a result of confounding.

Conclusions-The $\mathrm{SO}_{2}$ density (or that of compounds closely associated with $\mathrm{SO}_{2}$ ) does not seem to have any short term effect on mortality in the Netherlands. $\mathrm{SO}_{2}$ levels higher than those currently reached in the Netherlands (above $200 \mu \mathrm{g} / \mathrm{m}^{3}$ ) may have a measurable effect on mortality and this should be investigated. Furthermore, analy- ses of the public health impact of outdoor air pollution should properly control for the lagged effects of temperature.

f Epidemiol Community Health 1993; 47: 121-126

Current knowledge of the short term effects of outdoor air pollution on mortality is still largely based on published reports of severe episodes that occurred decades ago. The best known episode occurred in London in 1952, when concentrations of sulphur dioxide $\left(\mathrm{SO}_{2}\right)$ and suspended particulates (British smoke) reached average daily levels of 3800 and $4500 \mu \mathrm{g} / \mathrm{m}^{3}$ respectively, and a considerable excess of mortality was registered. ${ }^{1}{ }^{2}$ Air pollution has been reduced substantially since then, at least in many western industrialised countries, but recent studies suggest that even at these lower levels episodes of increased air pollution are associated with raised mortality rates. ${ }^{3-11}$ When measured in terms of $\mathrm{SO}_{2}$ density, the threshold for short term effects on mortality is believed to lie around $500 \mu \mathrm{g} / \mathrm{m}^{32} 12$ or even around $150 \mu \mathrm{g} / \mathrm{m}^{3}$.

In the Netherlands from 1979-87 the average daily $\mathrm{SO}_{2}$ densities (measured by six stations distributed across the country) fluctuated around a median value of approximately $18 \mu \mathrm{g} / \mathrm{m}^{3}$ (table I). The maximum value registered was $398 \mu \mathrm{g} / \mathrm{m}^{3}$ (on 17.1.85), and on only 19 days was a value above $200 \mu \mathrm{g} / \mathrm{m}^{3}$ registered. There is, nevertheless, a rather strong association between $\mathrm{SO}_{2}$ density and daily mortality (figure 1). Daily mortality increases steeply with increasing air pollution, but the curve seems to level off at 'higher' values. This association persisted in a multiple regression analysis in which daily mortality was related to $\mathrm{SO}_{2}$ density, controlling for average daily temperature, difference between maximum and minimum temperatures, amount of precipitation, average wind speed, and incidence of influenza. After breaking down total mortality data into groups according to the specific causes of death, the association was strongest for chronic non-specific lung disease and pneumonia, conditions considered to be sensitive to the effects of air pollution. ${ }^{13}$

Because these preliminary findings suggested a very low threshold for the mortality effects of air pollution, they were investigated further in an analysis that is reported here. The main objective was to determine whether any further sources of confounding could have biased the effect estimates and to achieve a maximally complete control of confounding.

The $\mathrm{SO}_{2}$ density is seen here as an 'indicator' for outdoor air pollution or for the host of compounds 
Table I Sulphur dioxide ( $\mathrm{SO}_{2}$ ) air pollution in the Netherlands, 1979-87.
Figure 1 Plot of mortality from all causes versus pollution, 1979-87. Days have been grouped on the basis of average $\mathrm{SO}_{2}$ density (in $\mu \mathrm{g} / \mathrm{m}^{3} ; 0-4$ $5-9, \ldots \ldots, 120-124,125$ $134,135-144, \ldots . .195-$ 204, 205+). sulphur dioxide air

present in polluted air. A statistical association between $\mathrm{SO}_{2}$ density and mortality is therefore likely to be the result, at least partly, of one or more of these other pollutants.

\begin{tabular}{lr}
\hline $50 t h$ centile of average daily $\mathrm{SO}_{2}$ density $\left(\mu \mathrm{g} / \mathrm{m}^{3}\right)^{\star}$ & \\
1979 & $23 \cdot 95$ \\
1980 & $22 \cdot 04$ \\
1981 & $19 \cdot 46$ \\
1982 & $19 \cdot 59$ \\
1983 & $16 \cdot 00$ \\
1984 & $16 \cdot 90$ \\
1985 & $13 \cdot 11$ \\
1986 & $14 \cdot 61$ \\
1987 & $13 \cdot 09$ \\
$1979-1987$ & $17 \cdot 86$ \\
No of days by average $\mathrm{SO}_{2}$ density $\left(\mu \mathrm{g} / \mathrm{m}^{3}\right)$ & \\
$<100$ & 3190 \\
$100-199$ & 78 \\
$200-299$ & 13 \\
$\geq 300$ & 6 \\
\hline
\end{tabular}

*Average daily $\mathrm{SO}_{2}$ density was calculated as the arithmetic average of the 24 hour average values of six measurement stations

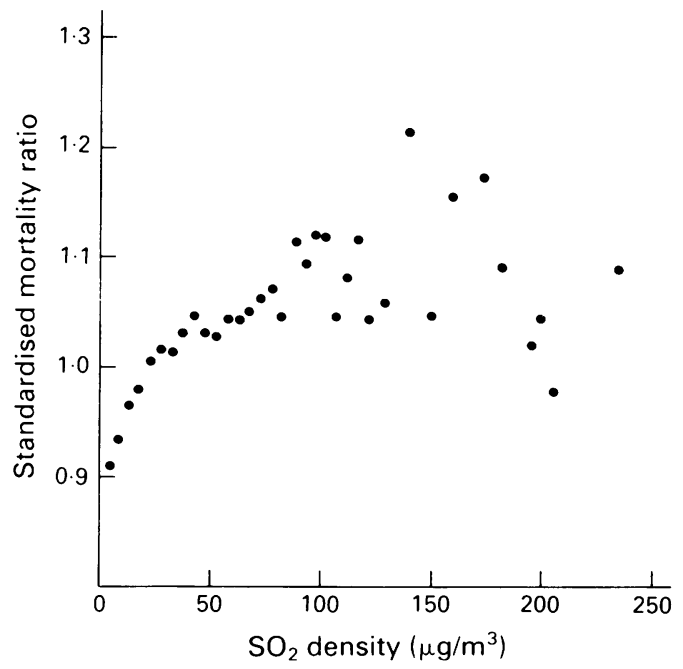

Table II Control variables: definition, association with mortality from all causes, association with sulphur dioxide air pollution

\begin{tabular}{|c|c|c|c|}
\hline \multirow[b]{2}{*}{ Variable name } & \multirow[b]{2}{*}{ Definition } & \multicolumn{2}{|l|}{ Association * with } \\
\hline & & $\begin{array}{l}\text { All cause } \\
\text { mortality }\end{array}$ & $\mathrm{SO}_{2}$ density \\
\hline Warm (0) & $\begin{array}{l}\text { Average temperature in degrees above } \\
16.5^{\circ} \mathrm{C} \text {, lag }=0 \text { days }\end{array}$ & + & - \\
\hline Warm $(1-5)$ & Idem, lag $=1-5$ days & - & - \\
\hline Warm $(6-10)$ & Idem, lag $=6-10$ days & - & - \\
\hline Warm $(11-15)$ & Idem, lag $=11-15$ days & - & - \\
\hline Cold $(0)$ & $\begin{array}{l}\text { Average temperature in degrees below } \\
16.5^{\circ} \mathrm{C} \text {, lag }=0 \text { days }\end{array}$ & + & + \\
\hline Cold $(1-5)$ & Idem, $l a g=1-5$ days & + & + \\
\hline Cold $(6-10)$ & Idem, lag $=6-10$ days & + & + \\
\hline Cold $(11-15)$ & Idem, lag $=11-15$ days & + & + \\
\hline $\operatorname{Max}-\min (0)$ & $\begin{array}{l}\text { Difference between maximum and } \\
\text { minimum temperature in }{ }^{\circ} \mathrm{C} \text {, lag }=0 \\
\text { days }\end{array}$ & - & - \\
\hline Precipitation (0) & Precipitation $(\mathrm{mm}), \mathrm{lag}=0$ days & - & - \\
\hline Precipitation (1-5) & Idem, lag $=1-5$ days & - & - \\
\hline Humidity $(0)$ & Relative humidity $(\%)$, lag $=0$ days & + & + \\
\hline Humidity $(1-5)$ & Idem, lag $=1-5$ days & + & + \\
\hline Wind $(0)$ & Wind speed in $\mathrm{m} / \mathrm{s}$, lag $=0$ days & + & - \\
\hline Wind $(1-5)$ & Idem, lag $=1-5$ days & + & - \\
\hline Influenza (0) & $\begin{array}{l}\text { Influenza notifications per } 10000 \\
\text { person-days, lag }=0 \text { days }\end{array}$ & + & + \\
\hline Influenza $(1-5)$ & Idem, lag $=1-5$ days & + & + \\
\hline Year $(\ldots)$ & $\begin{array}{l}\text { Set of } 8 \text { dummy variables for the } \\
\text { calendar years } 1980-87 \text {, with } 1979=0\end{array}$ & $\begin{array}{l}\text { Decrease from } \\
1979-87\end{array}$ & $\begin{array}{l}\text { Decrease from } \\
1979-87\end{array}$ \\
\hline Month $(\ldots)$ & $\begin{array}{l}\text { Set of } 11 \text { dummy variables for the } \\
\text { months of the year, with January }=0\end{array}$ & $\begin{array}{l}\text { Decrease from } \\
\text { January to } \\
\text { August }\end{array}$ & $\begin{array}{l}\text { Decrease from } \\
\text { January to July }\end{array}$ \\
\hline Weekday $(\ldots)$ & $\begin{array}{l}\text { Set of } 6 \text { dummy variables for the days } \\
\text { of the week, with Monday }=0\end{array}$ & $\begin{array}{l}\text { Decrease from } \\
\text { Monday to } \\
\text { Sunday }\end{array}$ & $\begin{array}{l}\text { Decrease from } \\
\text { Wednesday to } \\
\text { Sunday }\end{array}$ \\
\hline
\end{tabular}

${ }^{\star}$ Sign of zero order, product-moment correlation
Data and methods

The numbers of deaths between 1 January 1979 and 31 December 1987 according to the day on which the death occurred and the cause of death (AM list of ICD-9) were supplied by the Netherlands Central Bureau of Statistics. The analysis reported here covers mortality from all causes as well as mortality from neoplasms (AM 12-19), cardiovascular diseases (AM 25-32), respiratory diseases (AM 33-35), and external causes (AM 48--53).

The person-days at risk, by age and sex, for 1 January of each year were extracted from publications based on the population registry of the Netherlands, which is continuously updated. Person-days at risk for other calendar days were estimated using linear interpolation. An exception was made for person-days at risk in the age group $<1$ year, which were calculated from the monthly number of births and were thereby adjusted for seasonal variation in the birth rate.

The person-days at risk, by age and sex for each day in the study period, and the age and sex specific mortality rates for the whole period, were used to calculate an 'expected' number of deaths for each day. This expected number of deaths was treated as an offset variable in the regression equation relating the number of daily deaths to a set of explanatory variables (see below).

The $\mathrm{SO}_{2}$ density data were available through a monitoring system run by the State Institute for Public Health and Environmental Protection (RIVM). ${ }^{14}$ This monitoring system consists of a network of measurement stations that measure continuously the concentration of pollutants in the air. For this analysis, six stations which together provide good coverage of the Netherlands population were chosen (Zaandam, Spijkenisse, Sellingen, Hellendoorn, Budel, and Bocholtz). An arithmetic average of the 24 hour average values for each of these stations was calculated to estimate the daily exposure of the Dutch population as a whole.

The $\mathrm{SO}_{2}$ densities were neither transformed nor lagged because additional analyses (not reported here) showed essentially the same results for log $\mathrm{SO}_{2}$, exp $\left(\mathrm{SO}_{2}\right)$, and lagged versions of untransformed $\mathrm{SO}_{2}$ (lags up to 20 days).

Because this analysis focused on a maximally complete control of confounding we tried to include as many potential confounders as possible (table II). These variables were selected on the basis of their (univariate) associations with both mortality and $\mathrm{SO}_{2}$ density. These potential confounders can be subdivided into the following groups.

\section{TEMPERATURE}

Daily variation in mortality has frequently been shown to be strongly associated with variation in outdoor air temperature. The relation between temperature and mortality is V shaped. ${ }^{13}{ }^{15-18} \mathrm{In}$ the Netherlands, mortality is lowest at an average daily temperature of $16.5^{\circ} \mathrm{C}$ and increases at both lower and higher temperatures. ${ }^{13} \mathrm{We}$ will therefore represent temperature with two complementary variables-'warm' ( 0 if temperature $\leq 16.5^{\circ} \mathrm{C}$; temperature minus $16.5^{\circ} \mathrm{C}$ at higher values) and 'cold' ( 0 if temperature $\geq 16.5^{\circ} \mathrm{C}$; $16.5^{\circ} \mathrm{C}$ minus temperature at lower values). 
There are also important lagged effects of temperature. ${ }^{13161920}$ In the Netherlands, the mortality effects of low temperatures ('cold') are strongest at lag times of one to five days, and diminish only gradually at longer lag times. The mortality effects of high temperatures ('warm') are positive on the same day but negative for later days, which suggests a compensatory effect. We will therefore account for these lagged effects by including in the regression equation the values of 'warm' and 'cold' for the same day (lag=0) and for previous days. In order to reduce multicollinearity these lagged variables were constructed for groups of previous days by averaging the values for 'warm' and 'cold' over these lag periods $(1-5,6-10$, 11-15, and 16-20 days previously respectively).

The difference between daily maximum and minimum temperatures ${ }^{21}$ was also included as a potential confounder.

The temperature data were all available from the Royal Netherlands Meteorological Institute (KNMI), and were measured at a central location in the Netherlands (De Bilt). Because the Netherlands is small, variations within the country in daily patterns of temperature are very limited.

\section{OTHER METEOROLOGICAL VARIABLES}

The amount of precipitation, air humidity, and wind speed are all weakly associated with daily mortality, ${ }^{20-24}$ both unlagged and with a short lag period 1-5 days previously). These variables were also available from the KNMI and apply to De Bilt.

\section{INFLUENZA INCIDENCE}

Variation in the incidence of influenza is a major determinant of variation in daily mortality..$^{25-28}$ In our analysis we found both unlagged effects and effects with a short lag period ( $1-5$ days). ${ }^{13}$ The information on influenza incidence was available from a monitoring system that collected data from approximately 45 general practices across the country. ${ }^{29}$

\section{SECULAR TREND}

To account for any secular trend in the mortality data, a nominal variable for calendar year was constructed. Mortality gradually decreased during the study period.

\section{SEASONAL VARIATION}

Although a seasonal variation in mortality is already covered (at least partly) by the temperature and other meteorological and influenza variables, we decided to include an additional nominal variable for month, to remove any residual confounding from this source.

\section{WEEKDAY}

Mortality varies by day of the week. ${ }^{30} 31$ In the Netherlands, mortality is generally highest on Mondays, and decreases irregularly during the week to reach its lowest value on Sundays. This pattern is not well understood but could easily lead to confounding, so we included a nominal variable for weekday in the regression equation.

The zero order associations between these potential confounders and both mortality and $\mathrm{SO}_{2}$ density are shown in table II. There is considerable potential for overestimating the effect of $\mathrm{SO}_{2}$ on mortality, because these association are frequently in the same direction.

Each variable included in the regression equation was checked for a non-linear relation with mortality by means of inspection of scatter plots and the addition of the square term to the regression equation. A clearly non-linear relation was found for temperature only (see above).

Although the results reported are based on a model that does not include any interaction terms between potential confounders, we also estimated the effect of $\mathrm{SO}_{2}$ density on mortality with a model which, in addition to the variables mentioned above, contained a number of interaction terms that have sometimes been shown to be independent predictors of mortality: product terms for both 'warm' and 'cold' with humidity and wind speed. ${ }^{32}{ }^{33}$ Because the results with this extended model were essentially the same, and the stability of parameter estimates considerably less (because of multicollinearity between the original variables and the interaction terms), we will report the simpler model only.

The daily number of deaths was related to $\mathrm{SO}_{2}$ density and a number of control variables by means of loglinear regression analysis. The regression equation reads as follows:

$$
\log \left(\hat{\mathrm{y}}_{i}\right)=\log \left(e_{i}\right)+\beta_{1} \mathrm{x}_{1}+\ldots .+\beta_{\mathrm{j}} \mathrm{x}_{\mathrm{j}}
$$

Where:

$\hat{y}_{i}=$ estimated number of deaths on day $i$;

$e_{i}=$ number of deaths on day $i$ that may be expected on the basis of age and sex specific population numbers on day $i$, and age and sex specific mortality rates for $1979-87$,

$\mathrm{x}_{1} \ldots \mathrm{x}_{\mathrm{j}}=\mathrm{j}$ independent variables,

$\beta_{1} \ldots \beta_{j}=$ regression coefficients.

Calculations were carried out with the GLIM computer package. ${ }^{34}$ Differences in scaled deviance between models were used to calculate the statistical significance of terms in the regression model. These $\mathrm{p}$ values must be interpreted cautiously, however, because of the residual autocorrelation present in the data. This problem is a result of the strong correlation between the observed numbers of deaths on adjacent days. This leads to overestimation of the statistical significance of associations between mortality and independent variables.

\section{Results}

The results of the analysis of the effect of $\mathrm{SO}_{2}$ density on mortality from all causes are presented in tables III and IV. Table III presents the results obtained with a 'complete' regression model, containing all potential confounding variables. Table IV presents the results obtained with a number of more simple models, intended to identify the most important confounders.

The main results of our analysis are shown in the first row of table III. In a model containing temperature variables, other meteorological variables, influenza incidence, and the variables representing calendar year, month and weekday, in addition to $\mathrm{SO}_{2}$ density, the regression coefficient for the latter variable is small and suprisingly 


\begin{tabular}{|c|c|c|c|c|}
\hline \multirow{44}{*}{$\begin{array}{l}\text { Table III Regression } \\
\text { coefficients, standard } \\
\text { errors, and statistical } \\
\text { significance for all } \\
\text { independent variables } \\
\text { included in a model with } \\
\text { mortality from all causes as } \\
\text { the dependent variable. }\end{array}$} & $\begin{array}{l}\text { Independent } \\
\text { variable }\end{array}$ & $\begin{array}{l}\text { Regression } \\
\text { coefficient }\end{array}$ & $\begin{array}{l}\text { Standard } \\
\text { error }\end{array}$ & $\begin{array}{l}\text { Statistical } \\
\text { significance }\end{array}$ \\
\hline & $\overline{\mathrm{SO}_{2}}$ & -0.00010 & 0.00005 & 0.036 \\
\hline & Warm (0) & 0.01959 & 0.00113 & $<0.001$ \\
\hline & Warm $(1-5)$ & 0.00701 & 0.00160 & $<0.001$ \\
\hline & Warm (6-10) & -0.00146 & 0.00151 & 0.36 \\
\hline & Warm $(11-15)$ & -0.00727 & 0.00142 & $<0.001$ \\
\hline & Cold $(0)$ & -0.00251 & 0.00042 & $<0.001$ \\
\hline & Cold $(1-5)$ & 0.00699 & 0.00055 & $<0.001$ \\
\hline & Cold $(6-10)$ & 0.00184 & 0.00047 & $<0.001$ \\
\hline & Cold $(11-15)$ & 0.00249 & 0.00041 & $<0.001$ \\
\hline & $\operatorname{Max}-\min (0)$ & 0.00271 & 0.00041 & $<0.001$ \\
\hline & Precipitation (0) & 0.00376 & 0.00260 & 0.167 \\
\hline & Precipitation (1-5) & -0.00067 & 0.00487 & 0.991 \\
\hline & Humidity $(0)$ & 0.00041 & 0.00016 & 0.132 \\
\hline & Humidity $(1-5)$ & -0.00128 & 0.00021 & $<0.001$ \\
\hline & Wind $(0)$ & 0.00097 & 0.00093 & 0.430 \\
\hline & Wind $(1-5)$ & 0.00260 & 0.00134 & 0.052 \\
\hline & Influenza (0) & 0.00190 & 0.00293 & 0.52 \\
\hline & Influenza $(1-5)$ & 0.02338 & 0.00297 & $<0.001$ \\
\hline & Year $(1980)$ & -0.00522 & 0.00428 & \\
\hline & Year (1981) & -0.01354 & 0.00432 & \\
\hline & Year (1982) & -0.02378 & 0.00430 & \\
\hline & Year (1983) & -0.03586 & 0.00433 & $<0.001$ \\
\hline & Year (1984) & -0.04263 & 0.00423 & \\
\hline & Year (1985) & -0.04005 & 0.00420 & \\
\hline & Year (1986) & -0.05117 & 0.00425 & \\
\hline & Year (1987) & -0.06778 & 0.00425 & \\
\hline & Month (Feb) & -0.04111 & 0.00494 & \\
\hline & Month (Mar) & -0.03302 & 0.00524 & \\
\hline & Month (Apr) & -0.03711 & 0.00634 & \\
\hline & Month (May) & -0.02746 & 0.00738 & \\
\hline & Month (Jun) & -0.01035 & 0.00838 & \\
\hline & Month (Jul) & -0.02673 & 0.00910 & $<0.001$ \\
\hline & Month (Aug) & -0.04973 & 0.00918 & \\
\hline & Month (Sep) & -0.03155 & 0.00854 & \\
\hline & Month (Oct) & -0.01774 & 0.00724 & \\
\hline & Month (Nov) & -0.01281 & $\begin{array}{l}0.00558 \\
0.00486\end{array}$ & \\
\hline & Month (Dec) & -0.00317 & 0.00486 & \\
\hline & Weekday (Tue) & -0.00755 & 0.00361 & \\
\hline & Weekday (Wed) & -0.00718 & 0.00361 & \\
\hline & Weekday (Thu) & -0.00370 & 0.00361 & $<0.001$ \\
\hline & Weekday (Fri) & -0.00157 & 0.00361 & \\
\hline & Weekday (Sat) & -0.01276 & 0.00362 & \\
\hline & Weekday (Sun) & -0.03471 & 0.00364 & \\
\hline
\end{tabular}

negative, indicating lower mortality at higher air pollution levels (table III). Although this coefficient is statistically significant at conventional significance levels, the degree of residual autocorrelation present in the data $(r=0.125)$ suggests that the $p$ values must be interpreted cautiously.

If this estimate is compared with the coefficient obtained in a model with $\mathrm{SO}_{2}$ density as the only independent variable (table IV), it is clear that the univariate effect is heavily confounded. A positive univariate association of reasonable magnitude $(0 \cdot 00110$, indicating $0 \cdot 11 \%$ mortality increase with every $\mu \mathrm{g} / \mathrm{m}^{3}$ increase in $\mathrm{SO}_{2}$ density) dwindles to a much smaller value $(-0.00010)$ when all potential confounders are taken into account. Figure 2 illustrates that after controlling for these confounders, even the episode with the highest level of $\mathrm{SO}_{2}$ air pollution (in January 1985)

Table IV Estimated effect of sulphur dioxide $\left(\mathrm{SO}_{2}\right)$ density on mortality from all causes controlling for different sets of confounding variables

\begin{tabular}{|c|c|c|}
\hline \multirow[b]{2}{*}{ Regression model } & \multicolumn{2}{|c|}{ Estimated effect of $\mathrm{SO}_{2}$ density on all cause mortality } \\
\hline & Regression coefficient & Standard error \\
\hline No control variables & 0.00110 & 0.00003 \\
\hline \multicolumn{3}{|l|}{ Controlling for only:* } \\
\hline Warm $(11-15)$ & 0.00098 & 0.00003 \\
\hline Cold $(0)$ & 0.00034 & 0.00004 \\
\hline Cold $(1-5)$ & 0.00006 & 0.00004 \\
\hline Cold $(6-10)$ & 0.00022 & 0.00004 \\
\hline Cold $(11-15)$ & 0.00038 & 0.00004 \\
\hline Month (..) & 0.00042 & 0.00004 \\
\hline Influenza $(0)$ & 0.00071 & 0.00003 \\
\hline Influenza $(1-5)$ & 0.00072 & 0.00003 \\
\hline Controlling for all potential confounderst & -0.00010 & $0 \cdot 00005$ \\
\hline \multicolumn{3}{|l|}{$\begin{array}{l}\text { Controlling for all potential confounders } \\
\text { except: } \neq\end{array}$} \\
\hline Cold $(1-5)$ & 0.00004 & 0.00004 \\
\hline Year $(\ldots)$ & 0.00007 & 0.00004 \\
\hline
\end{tabular}

* Only those variables are mentioned here which, when introduced separately into the $\mathrm{SO}_{2}$ mortality model, change the $\mathrm{SO}_{2}$ coefficient by more than 0.00010 (in either direction). tAll variables mentioned in Table II

fOnly those variables which, when deleted from the complete model, change the $\mathrm{SO}_{2}$ coefficient by more than 0.00010 (in either direction) are mentioned here. was not accompanied or followed by a detectable rise in mortality.

To see which variable contributes most to the confounding, we introduced all these variables separately into the simple model containing only $\mathrm{SO}_{2}$ density (table IV). Only eight variables reduce the (univariate) $\mathrm{SO}_{2}$ coefficient by more than approximately $10 \%(0.00010$ in absolute terms). Low temperature, both unlagged and lagged, has the strongest confounding effects. But while a low temperature on the same day reduces the $\mathrm{SO}_{2}$ coefficient to a value still substantially positive, it is only with a lag period of one to five days that the $\mathrm{SO}_{2}$ coefficient is reduced to near zero. Season (measured by the variable 'month (..)') also seems to be a confounder, but this may be the result of a close association between season and temperature. The influenza incidence also acts as a modest confounder.

In addition to this 'forward selection' technique we also used a 'backward elimination' procedure. When all the variables (including 'cold (1-5)') are deleted separately from the model presented in table III, only two variables seem to have unique confounding properties. Only the deletion of 'cold (1-5)' and 'year (..)' is associated with a change in the $\mathrm{SO}_{2}$ coefficient of more than 0.00010 . While this confirms the importantce of 'cold (1-5)' as a confounder, it should be noted that even after its deletion the effect estimate of $\mathrm{SO}_{2}$ remains very small. This indicates that controlling for (combinations of) other variables in the model also removes a substantial part of the confounding effects of 'cold (1-5)'.

Because of multicollinearity between independent variables, the estimates for separate parameters obtained with the complete model (table III) must be interpreted cautiously. Most of the tendencies, however, are quite plausible, and support the credibility of the model:

(1) High temperatures are associated with higher mortality, although at longer lag times the association becomes negative, suggesting that the higher risks of dying during hot days mainly affects terminal patients.

(2) Low temperatures are also associated with higher mortality, especially on subsequent days; the negative association between lower temperature and mortality on the same day may be the result of multicollinearity.

(3) The influenza incidence is an independent predictor of mortality, especially one to five days later.

(4) Mortality has gradually decreased from 1979-87, which was already clear from the univariate analyses (table II). The nominal variables representing months, however, have rather different coefficients in the multivariate analysis. After taking into account the variation in meteorological conditions and influenza incidence, mortality still is highest in January and lowest in August, but the pattern of decline between January and August is irregular. Mortality is highest on Monday, drops steeply on Tuesday, rises again until Friday, and reaches its lowest value on Sunday.

Although there does not seem to be an effect of $\mathrm{SO}_{2}$ density on mortality from all causes, it is possible that there is such an effect for one or several specific causes of death-for example, 


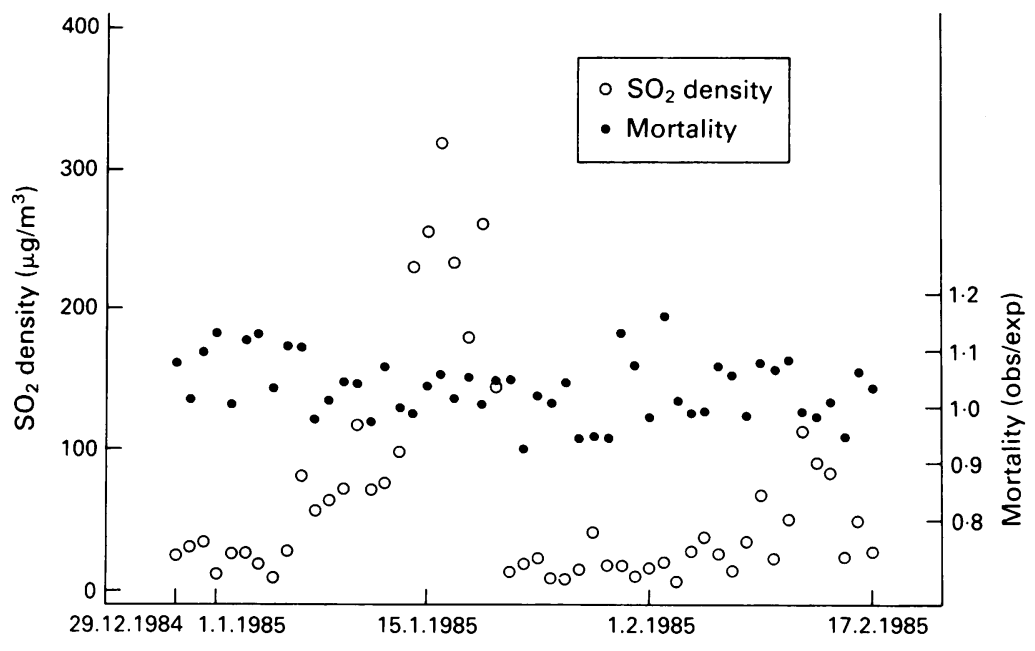

Figure 2 Mortality from all causes (adjusted for the effect of all the potential confounders) and $\mathrm{SO}_{2}$ density during the episode with the highest registered levels is of $\mathrm{SO}_{2}$ density of the period 1979-87. The figure shows the ratio of the observed mortality rate and the mortality rate predicted by a model containing all the variables (except $\mathrm{SO}_{2}$ density) of Table III.

respiratory diseases. After controlling for potential confounders, however, the association between $\mathrm{SO}_{2}$ density and specific causes of death also disappears (table V). While univariate associations suggest an effect of air pollution on mortality from neoplasms, cardiovascular diseases, respiratory diseases, and external causes as well as mortality from all other causes, the multivariate analyses produced the same inconsistent effect estimates as found for mortality from all causes. The difference between the univariate and multivariate effect estimates (regression coefficients) is largest for respiratory diseases. While the univariate estimate suggested a strong effect of $\mathrm{SO}_{2}$ density on respiratory disease mortality (twice as strong as the effect on mortality from all causes), the multivariate estimate is negative, although not statistically significantly so.

\section{Discussion}

Epidemiological investigations of the effect of air pollution on mortality usually try to adjust for the influence of potential confounders, including meteorological variables. ${ }^{379-11}$ Temperature is almost always recognised as a potential confounder, but lagged effects of temperature are not commonly taken into account. ${ }^{5}$ Our analysis shows that use of current temperature only may lead to seriously biased results. In the Netherlands, episodes of air pollution, as measured by $\mathrm{SO}_{2}$ density, frequently follow a period with relatively low temperatures. This may be the result of both atmospheric conditions and the increased use of fuel for heating. As the mortality effects of

Table $V$ Estimated effect of sulphur dioxide (SO, density on cause specific mortality

\begin{tabular}{|c|c|c|c|c|}
\hline \multirow[b]{2}{*}{ ICD chapter } & \multicolumn{2}{|c|}{ Univariate effect of $\mathrm{SO}_{2}$ density } & \multicolumn{2}{|c|}{ Multivariate effect of $\mathrm{SO}_{2}$ density ${ }^{*}$} \\
\hline & $\begin{array}{l}\text { Regression } \\
\text { coefficient }\end{array}$ & Standard error & $\begin{array}{l}\text { Regression } \\
\text { coefficient }\end{array}$ & Standard error \\
\hline $\begin{array}{l}\text { Neoplasms } \\
\text { Cardiovascular diseases } \\
\text { Respiratory diseases } \\
\text { External causes } \\
\text { All other causes } \\
\text { All causes }\end{array}$ & $\begin{array}{l}0.00028 \\
0.00164 \\
0.00231 \\
0.00059 \\
0.00070 \\
0.00110\end{array}$ & $\begin{array}{l}0.00006 \\
0.00005 \\
0.00013 \\
0.00015 \\
0.00008 \\
0.00003\end{array}$ & $\begin{array}{r}-0 \cdot 00017 \\
-0.00006 \\
-0.00033 \\
0 \cdot 00010 \\
-0 \cdot 00009 \\
-0.00010\end{array}$ & $\begin{array}{l}0.00009 \\
0.00007 \\
0.00019 \\
0.00021 \\
0.00011 \\
0.00005\end{array}$ \\
\hline
\end{tabular}

low temperatures last for several days (weeks even), the $\mathrm{SO}_{2}$ density cannot fail to become statistically associated with mortality.

It is interesting that the effect of controlling for a more complete set of potential confounders is larger for mortality caused by respiratory diseases than for other causes of death. In a preliminary analysis, the large univariate association between $\mathrm{SO}_{2}$ density and mortality from respiratory diseases was interpreted by us as evidence for a causal association between air pollution and mortality. The degree of confounding by lagged effects of low temperatures, however, proved to be higher for respiratory diseases, because the increase in mortality after cold spells is greater for respiratory conditions than for other causes of death. ${ }^{13}$

Although the regression model containing all potential confounders suffers from some redundancy, the absence of a clear association between $\mathrm{SO}_{2}$ density and mortality is not a result of overspecification of the model. The univariate effect of $\mathrm{SO}_{2}$ density on mortality disappears almost completely when only one potential confounder, low temperature lagged for one to five days, is taken into account. This variable fulfills all the criteria for being considered as a confounder, since it:

is an independent determinant of mortality (it is associated with mortality even after controlling for $\mathrm{SO}_{2}$ density-see table III);

is associated with $\mathrm{SO}_{2}$ density (see table II);

and is not part of the causal chain between $\mathrm{SO}_{2}$ density and mortality (cold spells cannot be a result of high $\mathrm{SO}_{2}$ density).

Controlling for the lagged effects of temperature eliminates an otherwise anomalous finding: an association between $\mathrm{SO}_{2}$ density and mortality at rather low levels of air pollution. Average $\mathrm{SO}_{2}$ density seldom reaches levels above $200 \mu \mathrm{g} / \mathrm{m}^{3}$ in the Netherlands as a whole (table I), so it seems that the threshold for a measurable effect on mortality should be sought at or above that level. This is not to say, of course, that the threshold for other short term effects-for example, on morbidity, ventilatory function, or respiratory complaints-or for long term effects is equally high.

It is also possible that other pollutants have measurable effects on mortality in the Netherlands. The $\mathrm{SO}_{2}$ density is simply an indicator of a host of outdoor air pollutants, especially those present in winter smog, such as carbon monoxide and black smoke. It is much less an indicator of summer smog, which is high in ozone, nitrogen dioxide, and other photochemical compounds. Information on the pollutants present in summer smog was not available to us during this analysis, but these other air pollutants should certainly be included in a complete analysis of the effects of outdoor air pollution on mortality.

We conclude that there is no evidence for a short term effect of $\mathrm{SO}_{2}$ density (and, by implication, density of pollutants that are closely associated with $\mathrm{SO}_{2}$ ) on mortality in the Netherlands. Furthermore, analyses of the public health impact of outdoor air pollution, including that by other compounds, should properly control for the important lagged effects of temperature.

This study was supported financially by the Ministry of Welfare, Public Health and Culture, Rijswijk, the Netherlands. 
The State Insitute for Public Health and Environmental Protection (RIVM) kindly supplied the sulphur dioxide density data.

1 Logan WPD. Mortality in the London fog incident. Lancet, 1953; i: 336-8.

2 Holland WW, Bennet AE, Cameron IR, et al. Health effects of particulate pollution: reappraising the evidence. $A m \mathcal{F}$ Epidemiol 1979; 110: 527-659.

3 Buechley RW, Riggan WB, Hasselblad V, van Bruggen JB. $\mathrm{SO}_{2}$ levels and perturbations in mortality. A study in the New York-New Jersey metropolis. Arch Environ Health 1973; 27: 134-7.

4 Mazumdar S, Schimmel H, Higgins ITT. Relation of daily mortality to air pollution: an analysis of 14 London winters, 1958/59 1971 72. Arch Environ Health 1982; 37: $213-20$.

5 Mazumdar S, Sussman N. Relationships of air pollution to health: results from the Pittsburgh study. Arch Environ health: results from the

6 Schimmel H, Murawski TJ. The relation of air pollution to mortality. F Ocrup Med 1976; 18: 316-33.

7 Schwartz J, Marcus A. Mortality and air pollution in London: a time series analysis. Am f Epidemiol 1990; 131: 185-94.

8 Derriennic F, Richardson S, Mollie A, Lellouch J. Shortterm effects of sulphur dioxide pollution on mortality in two French cities. Int $\mathcal{F}$ Epidemiol 1989; 18: 186-97.

9 Hatzakis A, Katsouyanni K, Kalandidi A, Day N, Trichopoulos D. Short-term effects of air pollution on Trichopoulos D. Short-term effects of air pollution
mortality in Athens. Int $\mathcal{F}$ Epidemiol 1986; 15: 73-81.

10 Katsouyanni K, Karakatsani A, Messari I, Touloumi G, Hatzakis A, Kalandidi A, et al. Air pollution and causeHatzakis A, Kalandidi A, et al. Air pollution and causespecific mortality

11 Loewenstein JC, Bourdel MC, Bertin M. Influence de la pollution atmosphérique ( $\mathrm{SO}_{2}$-poussiéres) et des conditions météorologiques sur la mortalité à Paris entre 1969 et 1976. Rev Epidemiol Santé Publique 1983; 31: 143-61.

12 World Health Organisation. Air quality criteria and guides for urban air pollutants. Geneva; WHO. 1979. Technical Report Series no 506.

13 Kunst AE Looman CWN, Mackenbach JP. Determinants of daily variation in mortality (in Dutch). Tijdschrift Sociale of daily variation in mortality (in D.

14 Rijksinstituut voor Volksgezondheid en Milieuhygiëne. National air quality monitoring network; technical description. Bational air quality monizen: RIVM, 1989.

15 Alderson MR. Season and mortality. Health Trends 1985; 17: $87-96$.
16 Bull GM, Morton J. Environment, temperature and death rates. Age Ageing 1978; 7: 210-224.

17 Bull GM. Meteorological correlates with myocardial end cerebral infarction and respiratory disease. British fournal of Preventive and Social Medicine 1973; 27: 108-13.

18 Rogot E, Padgett SJ. Associations of coronary and stroke mortality with temperature and snowfall in selected areas of the United States, 1962-1966. Am $\mathcal{F}$ Epidemiol 1976; 103; 565-75.

19 Rose G. Cold weather and ischaemic heart disease. British fournal of Preventive and Social Medicine 1966; 20: 97-100. 20 Bull GM. The weather and deaths from pneumonia. Lancet 1980; i: $1405-08$.

21 Driscoll DM. The relationship between weather and mortality in ten major metropolitan areas in the United States, 1962-1965. Int F Biometeorol 1971; 15: 23-39.

22 Shumway RH, Azari AS, Pawitan Y. Modeling mortality fluctuations in Los Angeles as functions of pollution and weather effects. Environ Res 1988; 45: 224-41.

23 Thurston GD, Ito K, Lippmann M, Hayes C. Reexamination of London, England, mortality in relation to Reexamination of London, England, mortality in relation to
exposure to acidic aerosols during 1963-1972 winters. exposure to acidic aerosols during 1963-
Environ Health Perspect 1989; 79: 73-82.

24 Goldsmith JR, Griffith H, Detels R, et al. Emergency room admissions, meteorological variables, and air pollutants. A admissions, meteorological variables, and air pollut

path analysis. Am $\mathcal{F}$ Epidemiol 1983; 118: 759-78.
25 Tillet HE, Smith JWG, Gooch CD. Excess deaths attibutable to influenza in England and Wales: Age at death and certified cause. Int $\mathcal{F}$ Epidemiol 1983; 12: 344-52.

26 Lui KJ, Kendal AP. Impact of influenza epidemics on mortality in the United States from October 1972 to May 1985. Am f Publ Health 1987; 77: 712-16.

27 Glezen WP, Payne AA, Snyder DN, Downs TD. Mortality and influenza. F Infect Dis 1982; 148: 313-21.

28 Monto AS. Influenza: quantifying morbidity and mortality. Am $\mathcal{F}$ Med 1987; 82 (suppl 6A): 20-5.

29 Bartelds AIM. Continuous morbidity registration in general practice sentinel stations. Utrecht: NIVEL, 1980-1988.

30 Rogot E, Fabsitz R, Feinleib M. Daily variation in USA mortality. Am F Epidemiol 1976; 103: 198-211.

31 Näyhä S. Short and medium-term variations in mortality in Finland. Scand f Soc Med 1980; suppl 21: 1-101.

32 Gill JS, Davies P, Gill SK, Beevers DG. Wind-c Beevers DG. Wind-chill and the seasonal variation of cerebrovascular disease. $f$ Clin Epidemiol 1

Ohno $Y$, Horibe $H$, Hayakawa $N$, Aoki N, Okada $H$ Biometeorologic studies on cerebrovascular diseases. IV. Evaluation of meterological factors, their changes or combinations on the ocurrence of cerebrovascular accident. fapanese Circulation fournal 1970; 39: 69-75.

34 Baker RJ, Nelder JA. GLIM manual (release 3). Oxford: Numerical Algorithms Group, 1987. 